\title{
Blended Psychotherapy: Treatment Concept and Case Report for the Integration of Internet- and Mobile-Based Interventions into Brief Psychotherapy of Depressive Disorders
}

\author{
Ingrid Titzler ${ }^{\mathrm{a}}$ Viktoria Egle $^{\mathrm{a}}$ Matthias Berking ${ }^{\mathrm{a}}$ Corinna Gumbmann ${ }^{\mathrm{b}}$ \\ David Daniel Ebert ${ }^{\mathrm{a}, \mathrm{c}}$ \\ aLehrstuhl für Klinische Psychologie und Psychotherapie, Friedrich-Alexander-Universität Erlangen-Nürnberg, \\ Erlangen, Germany; ${ }^{b} \mathrm{CIP}$-Ambulanz Erlangen, Centrum für Integrative Psychotherapie, Erlangen, Germany; ${ }^{\mathrm{C} S e c t i o n}$ \\ of Clinical Psychology, Faculty of Behavioral and Movement Sciences, VU Amsterdam, Amsterdam, The Netherlands
}

\section{Keywords \\ Blended psychotherapy · Internet-/mobile-assisted brief psychotherapy · Depressive disorder · Case report}

\section{Abstract}

Background: Blended psychotherapy (bPT) is a treatment that integrates internet- and mobile-based interventions into out-/inpatient psychotherapy. It can enrich the therapy by using online-based treatment modules as therapeutic extension that patients use time- and location-independently between face-to-face sessions. It could potentially improve the efficacy of psychotherapy and increase the number of treated persons through saved therapist time. The case report aims to facilitate the understanding of the blended treatment components. Case Report: A 4-month short-time depression treatment with six face-to-face therapy sessions, six online lessons, and app ratings of a 48-year-old female patient is presented based on the CARE guidelines and quantitative and qualitative measures (treatment documentation). Depressive symptoms were clinically significantly reduced (PHQ-9, 0-27: T0 = 17; T1 = 7) from a moderately severe to a subclinical-mild degree, and no diagnostic criteria were met in the 12-month follow-up diagnostic interview.
\end{abstract}

The patient showed a maximum treatment satisfaction (ZUF-8, 8-32: T1 = 32) and adherence and rated the therapeutic working alliance (WAI, 12-60: T1 = 57) highly positive. Conclusion: bPT reduced depressive symptoms for this patient. Strengths of the treatment were the facilitated use of the internet-based elements with a full-time job and the individualization within the face-to-face sessions through the therapist. Treatment success was limited by the predetermined six sessions, which hindered addressing all topics and conducting relapse prevention.

○ 2019 S. Karger AG, Basel

Blended Psychotherapy - verzahnte Psychotherapie: Behandlungskonzept und Fallbericht zur Integration von Internet- und Mobil-basierten Interventionen in die Kurzzeittherapie von depressiven Störungen

\section{Schlüsselwörter}

Blended Psychotherapy · Verzahnte Psychotherapie . Internet-/mobilgestützte Kurzzeittherapie · Depression . Fallbericht

\section{KARGER}

(C) 2019 S. Karger AG, Basel 


\section{Zusammenfassung}

Hintergrund: Blended Psychotherapy (bPT) ist ein Behandlungskonzept zur Integration von Internet-/Mobilbasierten Interventionen in die ambulante/stationäre Psychotherapie. Es kann den Therapieprozess bereichern, indem Online-basierte Behandlungselemente als verlängerter therapeutischer Arm genutzt und zwischen den Therapiesitzungen von PatientInnen zeit- und ortsunabhängig bearbeitet werden. Dadurch könnten die Effektivität von Psychotherapie potenziell verbessert oder mehr Therapieplätze durch die eingesparte Therapeutenzeit angeboten werden. Der Fallbericht soll ein Verständnis der Verzahnung der Behandlungselemente ermöglichen. Fallbericht: Die viermonatige Kurzzeit-Depressionsbehandlung einer 48-jährigen Patientin mit sechs Face-toFace-Therapiesitzungen, sechs Online-Lektionen und App-Ratings wird nach den CARE-Richtlinien und auf Basis quantitativer und qualitativer Daten (Behandlungsdokumentation) dargestellt. Die depressive Symptomatik reduzierte sich im Behandlungsverlauf klinisch signifikant (Patient Health Questionnaire [PHQ-9], 0-27: T0 = 17 $\mathrm{T} 1=7$ ) von einer mittel-schwergradigen zu einer subklinisch-milden Ausprägung und erfüllte im 12-Monats-Diagnostikinterview keine klinischen Diagnosekriterien. Die Patientin zeigte eine maximale Behandlungszufriedenheit (Fragebogen zur Patientenzufriedenheit [ZUF-8] 8-32: T1 = 32) sowie Adhärenz und bewertete die therapeutische Beziehung sehr positiv (Working Alliance Inventory [WAI], 12-60:T1 = 57). Schlussfolgerung: bPT war bei dieser Patientin geeignet, um depressive Symptome zu reduzieren. Stärken der Behandlung waren die gute Integrierbarkeit der Online-Behandlung in die Berufstätigkeit der Patientin und die Individualisierung in den Therapiegesprächen durch die Therapeutin. Die Vorgabe von sechs Therapiesitzungen schränkte den Behandlungserfolg insofern ein, dass nicht alle Behandlungsthemen therapeutisch bearbeitet und keine Rezidivprophylaxe durchgeführt werden konnten.

\section{Background}

Depressive disorders are highly prevalent, have a high comorbidity rate [Jacobi et al., 2014], and are considered a public health problem, with one of the highest burden of disease rankings [World Health Organization, 2008]. Yet there is a considerable care deficit, with only $34.6 \%$ of those affected (12-month prevalence) utilizing outpatient or inpatient care by physicians/psychotherapists [Mack et al., 2014], and 64.1\% seeing only primary care doctors and 25\% seeing specialists [Gerste and Roick, 2014]. The waiting time for psychotherapy is an average of 19.9 weeks, which increases the risk of exacerbation

and chronification [Bundespsychotherapeutenkammer, 2018].

One possible solution could be the use in psychotherapy of the new media as a means of care delivery, which would convey the psychotherapeutic interventions by other communication channels and would correspond to the role of digitalization in patients' everyday lives. This shifts therapy from personal contact to virtual space, providing therapeutic techniques and content via the Internet- and mobile-based programs (the web, apps) [Ebert et al., 2018].

Previous research confirms that Internet- and mobilebased interventions (IMIs) can be effective for treatment of depression. Thus, meta-analyses of studies of depression yield that IMIs showed high effect sizes, with Hedges' $g=0.90$ compared to waiting control groups (number of studies $k=19$, study participants included $N=1,650$ ) [Königbauer et al., 2017] and guided IMIs attained significantly higher response rates (odds ratio $[\mathrm{OR}]=2.49$ ) and remission rates $(\mathrm{OR}=2.41)$ than did control groups ( $k=24, N=4,889$ ) [Karyotaki et al., 2018]. This shows that guidance (e.g., support by an e-coach) is associated with greater symptom reduction, increased adherence, and fewer dropouts [Baumeister et al., 2014]. Furthermore, IMIs with therapeutic guidance can achieve efficacy similar to cognitive behavioral therapy (CBT) (metaanalysis with $k=20, N=1,418$, of which $k=4$ were for depressive symptoms) [Carlbring et al., 2018]. For patients who are open to that but prefer personal contact, an integrated and blended combination treatment could be considered.

The applications of blended psychotherapy (bPT) can be sequential (e.g., IMIs for bridging the waiting time before face-to-face therapy or for follow-up care afterwards) or have an integrating function (e.g., IMIs for support, intensification, or improvement of the resource allocation of face-to-face therapy or as a component of integrated care) [Erbe et al., 2017; Baumeister et al., 2018]. bPT combines IMIs with classic face-to-face psychotherapy and could thereby combine the best of both worlds, by means such as (a) personal contact with the psychotherapist, (b) room for individualization in therapy sessions, (c) the opportunity to use the IMIs by working people or those in underserved areas, independent of time and place, (d) outsourcing of treatment elements to IMIs and investment of the therapist's time saved to treat more patients, (e) supporting structured treatment, (f) repeated, daily recording of emotions and behavior patterns by an ecological momentary assessment via smartphone or wearable, or (g) potentially increasing effectiveness by intensifying therapy. However, there are also challenges for patients and therapists, including (a) technical know-how, (b) ensuring data protection, (c) costs of acquisition/development/licensing (currently there is no standard health in- 
surance benefit), (d) access to the Internet/computer/ smartphone, and/or (e) organizational requirements.

Initial research has shown promising results for the clinical efficacy of bPT. Increasing the treatment intensity through adjuvant IMIs makes it possible to increase efficacy while keeping face-to-face therapy time constant: the supplementary online component achieved moderate effect sizes of Cohen's $d=0.51$ compared to outpatient psychotherapy (85\% CBT) [Berger et al., 2018] and $d=$ 0.44 compared to inpatient psychodynamic psychotherapy [Zwerenz et al., 2017]. A meta-analysis showed that with additional mobile technology (apps, short message service) for psychological interventions in the case of psychiatric or somatic disorders $(k=10, N=1,499)$, greater treatment success is possible than with intervention alone (effect size $=0.27, p<0.05$ ) [Lindhiem et al., 2015]. Consistent effects can be achieved by reducing face-to-face therapist time (potential savings of 50-86\%) and replacing it with IMIs [Erbe et al., 2017]. Thus, a CBT-based bPT with $50 \%$ face-to-face and $50 \%$ online sessions was not inferior to classical CBT psychotherapy, and attained a very high effect size of $d=0.87$ compared to pure CBT online treatment [Sethi et al., 2010]. Smartphone support of short-term CBT (four face-to-face sessions, potential savings of $47 \%$ of therapist time) yielded results in reducing depressive symptoms equivalent to a classic shortterm CBT (ten sessions) [Ly et al., 2015]. This also suggests the potential for a cost-saving and effective alternative to traditional psychotherapy. It is highly relevant that there have been positive findings about acceptance of bPT both among therapists [Kooistra et al., 2016; Titzler et al., 2018] and among patients [van der Vaart et al., 2014; Etzelmueller et al., 2018], in particular computer-based CBT in underserved rural areas [Vallury et al., 2015].

bPT is an integrated treatment concept that optimally utilizes the technological possibilities of the new media in combination with classical therapeutic methods. It allows psychotherapy to be offered over the Internet independently of time and place, in combination with personal contact. bPT is already being implemented in healthcare in the Netherlands (www.mindway.nl), investigated as routine care in implementation studies [Vis et al., 2015], and put into practice in individual research/model projects in Germany [Etzelmueller et al., 2018; Titzler et al., 2018; Baumeister et al., 2019; Kemmeren et al., 2019]. Given that the course of such treatment is little known, we present a description and concretization based on a case report.

\section{Description of the Treatment Elements of the bPT}

\section{Therapy Format}

The bPT we used is an outpatient short-term therapy that integrates face-to-face therapy sessions with IMIs based on CBT. During the treatment period of ca. 13 weeks, seven sequential online lessons (four of which are therapeutically divided into Modules A and B and are to be worked on weekly) are complemented every 2 weeks in a ratio of 2:1 by six personal therapy sessions and continuous app-based measurements of progress (various emotional, cognitive, and behavior-related parameters) (Fig. 1). Each treatment starts with a face-to-face on-site therapy session, alternating with weekly online and biweekly face-to-face sessions, and ending with an online lesson on relapse prevention.

\section{Face-to-Face Therapy Sessions}

Initial Interview and Technical Introduction. The first face-to-face session has specific goals such as building the therapeutic relationship, technical introduction to the web-/app-based treatment elements (e.g., installation, login, dealing with inhibitions, pdf handbooks), as well as explaining and scheduling the treatment process. The other five face-to-face therapy sessions are scheduled on a biweekly basis, allowing for flexible adjustments during crises or delays in performing the online lessons due to illness or vacation.

Second to Fifth Face-to-Face Therapy Sessions. The therapist structures each session to include the following components: (a) integrating online treatment elements, i.e., reviewing online lessons and discussing app measurements of progress, (b) clarifying issues of comprehension and technical difficulties, (c) in-depth discussion of the web content and exercises, (d) dealing with current stress or other topics of concern to the individu$\mathrm{al}$, and (e) blending and structuring the course of treatment, e.g., selection and scheduling of the next online lesson. In the second face-to-face session, the "Things worth Knowing" online lesson can be deepened by the creation of an individual vulnerability-stress model or a situational analysis. The sequence of subsequent online lessons can be freely selected and coordinated. The following interventions are proposed for deepening the process in the third to fifth face-to-face sessions: identification of barriers and resource activation for support in behavioral activation ("Getting Active" online lesson), using a step-by-step plan for cognitive restructuring ("Rethinking" online lesson), as well as systematic problem solving in one's own situations ("Solving Problems" online lesson).

Completion of Therapy. The sixth face-to-face session is designed for reflection on the treatment, reinforcement of progress, initiation of follow-up treatment if appropriate, discussion of prophylactic measures to prevent relapse, and activation of the "Preventing Relapse" online lesson. 


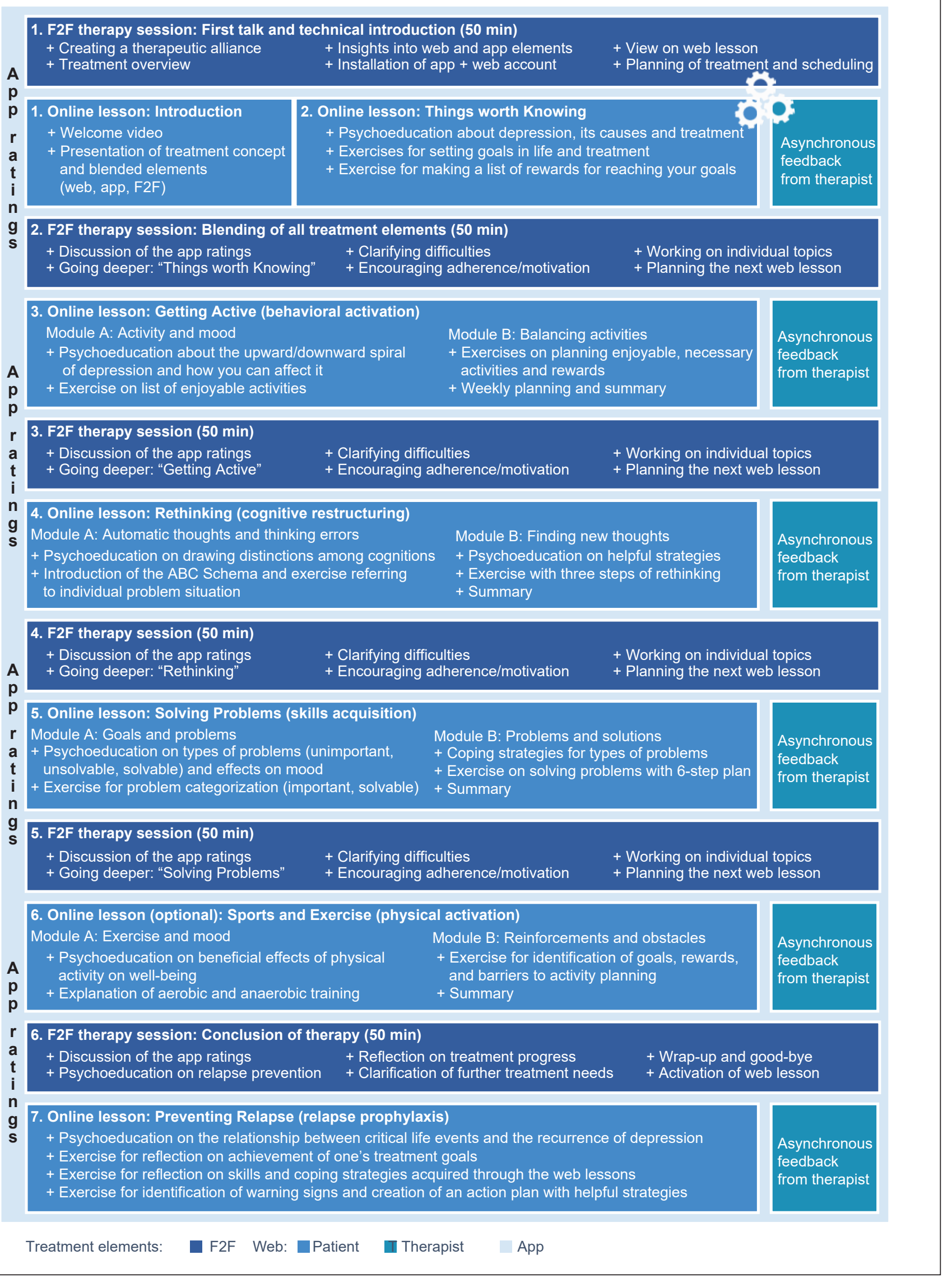

Fig. 1. Blending of face-to-face (F2F)/app/web treatment elements. 


\section{Online Treatment}

Web Treatment Program. The online treatment is performed on the Moodbuster platform (Platform ICT4D, Server University INESC Porto, Portugal), which uses password-encrypted access and does not require input of any personal data. The content can only be viewed by the patient and the therapist. The patient receives access to CBT-based online lessons according to evidence-based therapeutic techniques for treatment of depression (e.g., psychoeducation, behavioral activation, cognitive restructuring, training in problem solving, and relapse prevention) [Hautzinger, 2013]. Each lesson offers in-depth psychoeducation with video and text material, allowing patients to apply what they have learned to their own situation through interactive exercises. The sequence of online lessons can be selected individually in consultation with the therapist, with "Introduction" and "Things worth Knowing" mandatory at the beginning and "Preventing Relapse" at the end of treatment; "Sports and Exercise" is optional. Patients can view the current online lesson and work on it flexibly, track their app-based progress logs (e.g., mood, activity), schedule and evaluate activities on the calendar, and communicate with the therapist.

First Online Lesson, "Introduction." The introductory lesson welcomes the patient and describes the components (face-to-face, web, app) of the blended depression treatment.

Second Online Lesson, "Things worth Knowing." For the purpose of psychoeducation, patients are informed about the clinical picture of depression, its causes, and treatment options. Through exercises, they are instructed to reflect upon their life goals and treatment goals, as well as rewards to increase their treatment motivation.

Third Online Lesson, "Getting Active." For behavioral activation [Sturmey, 2009; Martell et al., 2010], a psychoeducational module provides information on the relationship between behavior and mood, as well as on the upward and downward spiral in depression. Patients plan the first enjoyable activities to enhance their wellbeing, and examine their own activity level, indicating for each activity how enjoyable it was and how frequently it was performed. To provide structure to the day, they are helped to find a balance between necessary and enjoyable activities and to overcome barriers to achievement. The calendar should comprise as many enjoyable activities as desired and as many necessary activities as required. After a week, both functionality and associated obstacles, as well as conditional mood changes, are scrutinized.

Fourth Online Lesson, "Rethinking." The goal is to correct dysfunctional cognitions in order to improve mood [Hawley et al., 2017]. An explanation is provided of negative automatic thoughts and thinking errors that lead to a distorted perception of reality. The patient learns seven steps to deal with that: (1) describing the starting position, (2) uncovering automatic thoughts and assessing credibility, (3) perceiving emotional strength, (4) recognizing thinking errors, (5) questioning one's thoughts and testing them for truthfulness, (6) finding a more helpful way of thinking, and (7) determining the credibility of the new thought. First, the patient analyzes with the ABC schema [Ellis, 1991] automatic thoughts, feelings, and thinking errors in certain situations and assesses the credibility of the automatic thought and the strength of the feelings evoked. Then, the thoughts are scrutinized and alternative, more helpful thoughts are formulated.

Fifth Online Lesson, "Solving Problems." In order to extend their skills for dealing with problems independently and efficiently [Cuijpers et al., 2018], patients are instructed to make a list of their own problems and assign them to different categories (unimportant, important and unsolvable, important and unsolvable). Then, a six-step plan is used to find systematic and solution-oriented ways of dealing with solvable problems.

Sixth Online Lesson, "Sports and Exercise" (Optional). Physical activities can have health and psychological benefits [Ledochowski et al., 2017]. Possibilities for affecting mood through exercise are illustrated, aerobic and anaerobic training are explained, and patients are instructed to plan their own sports activities. The patient is then reinforced by identifying goals, rewards, and possible obstacles to their achievement in everyday life.

Seventh Online Lesson, "Preventing Relapse." In reflection on the treatment, the patients should indicate their satisfaction with the treatment goals and report on the coping skills they acquired in each lesson. Warning signs and response options are addressed for relapse prevention. Finally, the patient is praised for successful completion of the treatment.

App-Based Measurements of Progress. On the smartphone app, the patient is regularly asked to record various parameters such as mood, sleep, activities, social contacts, self-esteem, and rumination, according to an algorithm (mood: $1 \times /$ day at randomly chosen time 10:00-22:00, other parameters: $1 \times /$ day in the first/last week of treatment, otherwise $1 \times /$ week; on a scale from $0=$ very bad to $10=$ very good). The data are synchronized with the online platform and used therapeutically (e.g., for progressdependent control of the treatment process, reinforcement for behavioral changes, perception of potential for influence through self-observation).

Therapeutic Guidance. Therapists support the patients online (on the news portal) if difficulties arise, and monitor the progress of the treatment and the app-based progress log on the therapist portal. They write weekly individualized feedback about the exercises or motivational reminder emails if the scheduled online lesson was not 
Dear Ms. Summer,

It's great that you have started the online lesson "Solving Problems." I would like to encourage you to consider dealing with your problems as you would do with a path with several stages. Step-by-step work to cope with problems can ease the worries wi nepressive and tense feelings they cause. One of the first important steps is to give the problem-solving process space and time.

As you have experienced today, there are different types of problems: unimportant, important unsolvable, and important solvable. I'm glad that you have already been able to independently categorize many of your problems. This structuring on its ow can bring you relief and ease tension. You might have already experienced this in the overcome the different types of problems. We can certainly discuss this in person You have also had the opportunity to take another look at the life goals that you formulated at the start of treatment. Be open to adjusting your goals if you believe a change is necessary. Sometimes needs or goals change - the important thing is that you take them seriously and work towards their fulfillment.

If you have any questions, feel free to contact me at any time. Best regards and have a nice weekend!

Yours truly,

Ms. Blume

Fig. 2. Example of feedback from the therapist to the patient.

completed. The weekly feedback templates can be customized to fit the patient's responses and situation (Fig. 2). The aims of the therapeutic guidance of the online treatment, in a time frame of ca. 25 min per week, are promotion of motivation and adherence (completion of the online lessons), reinforcement, reflection, and summary of the treatment progress.

\section{Method}

\section{Design}

In the context of a Europe-wide research project (www.e-compared.eu), the bPT for depression was evaluated between 2014 and 2017 for its efficacy and cost-effectiveness compared to routine care [Kleiboer et al., 2016; Kemmeren et al., 2019]. Of the 173 patients enrolled in primary care who met the inclusion/exclusion criteria (age at least 18, Patient Health Questionnaire [PHQ-9] $\geq 5$ in screening, major depression in the clinically structured interview, no severe comorbid psychiatric disease, no ongoing psychotherapy, access to the Internet), 86 were randomly assigned to the short-term bPT. The treating psychologists were enrolled in a continuing education program in psychological psychotherapy (CBT) and received training (treatment manual), continuous guidance, and monthly supervision.

In-depth insights into the treatment concept enable individual case analyses that make possible scientific findings about new interventions [Cohen, 2006; Virués-Ortega and Rodríguez, 2008]. The present case report was informed by the CARE guidelines [Gagnier et al., 2013] and was further adapted for this form of treatment on the basis of additional case report guidelines [Cohen, 2006; Virués-Ortega and Rodríguez, 2008] (see Checklist, online supplementary Table 1; see www.karger.com/ doi/10.1159/000503408 for all online supplementary material).

\section{Participants and Case Selection}

The patients in the bPT had an average age of 43.2 years $(\mathrm{SD}=$ 13.1 , range $=19-70)$, were predominantly female $(60.5 \%)$, highly educated (55.8\% with at least a high school diploma), employed (74.4\%), married (39.5\%), and urban residents (60.5\%).
Selection of treatment case considered criteria such as aboveaverage treatment adherence and treatment success (Reliable Change Index), as well as representativeness of patient characteristics (female, middle age). Other characteristics included employment, rural residence (high need for healthcare), and low education (rather atypical).

\section{Diagnostic Instruments}

The representation of treatment progress and results was based on evaluation of self-assessment instruments, clinically structured interviews, questionnaires, and clinical findings (therapist, primary care doctor). These were recorded over 12 months online or on paper at up to four measurement points for all persons involved in treatment.

Qualitative descriptions relied on evaluation of audio recordings and treatment documentation from the face-to-face sessions, as well as exports of the completed online intervention materials.

The following data were used for the quantitative evaluations: the PHQ-9 [Erbe et al., 2016] and the Quick Inventory of Depressive Symptomatology - Self-Report (QIDS-SR) [Rush et al., 2003] recorded depressive symptoms, and the Mini-International Neuropsychiatric Interview [Sheehan et al., 1998] was used for diagnosis. The EQ-5D-5L quality of life questionnaire [Herdman et al., 2011] covered health-related limitations and the Insomnia Severity Index (ISI) [Thorndike et al., 2011] covered sleep disorders. Treatment expectations were recorded by the Credibility and Expectancy Questionnaire (CEQ) [Devilly and Borkovec, 2000] and facets of treatment satisfaction by the Patient Satisfaction Questionnaire (ZUF-8) [Schmidt et al., 1989] and the System Usability Scale (SUS) [Brooke, 1996]. The working relationship with the therapist was assessed at the session level by the Bern Post Session Report (Patient Version, PSTB) [Flückiger et al., 2010] and after the end of treatment by the Working Alliance Inventory (WAISF) [Munder et al., 2010]. The adapted Technology Alliance Inventory - Online Therapy (TAI) covered the working alliance with the online treatment program. The Inventory for the Assessment of Negative Effects of Psychotherapy (INEP) [Ladwig et al., 2014] captured possible negative effects of the intervention. Furthermore, the web logfiles and app progress measurements (ecological momentary assessment) were evaluated and adherence calculated.

\section{Case Report}

\section{Patient Information at the Start of Treatment}

Demographic Characteristics. The 48-year-old woman, Ms. Mai (secondary school diploma, employed for 33 years, no children, name changed), lives in the countryside with her husband.

Symptoms, Medical History, and Physical Comorbidities. The patient reported a depressed mood, reduced interest or pleasure in almost all activities, loss of appetite, sleep disorders, decreased concentration, psychomotor agitation, fatigue, and lack of energy. These complaints, she said, developed in mid-2015 after years of sleep difficulties due to work overload and had recently led her to take sick leave. She had had two other depressive episodes (the first in her mid 20s). She did not know of any family history of psychiatric disorders; according to the primary care doctor's consultation report, there were accompanying physical comorbidities (trigeminal neuralgia, diseases of the musculoskeletal system).

Past and Current Treatments. Ms. Mai had been taking medication under the primary care doctor's care for 6 months because of her psychological complaints and had no previous experience with psychotherapy. The primary care doctor reported that there had 


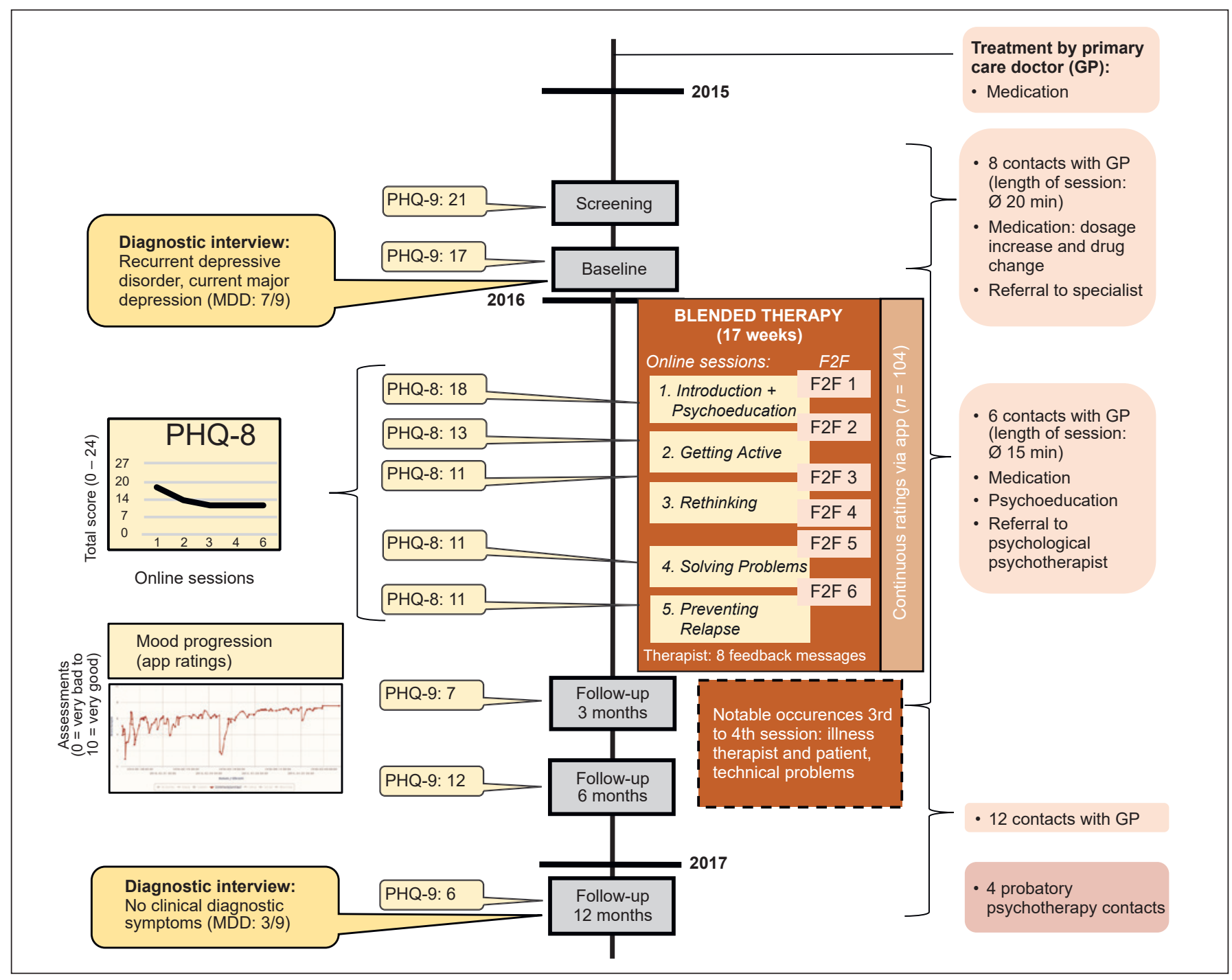

Fig. 3. Timeline of Ms. Mai's treatment and symptom progression. F2F, face-to-face; PHQ, Patient Health Questionnaire.

been eight consultations over the past 3 months and conditional implementation of the treatment for depression because of problematic appointment compliance and patient compliance. This treatment consisted of pharmacotherapy with increased dosage and drug change due to lack of response to antidepressants (venlafaxine, opipramol, citalopram, mirtazapine), active and watchful waiting, as well as referral for treatment by a specialist.

Prognosis, Expectations, and Preferences for Treatment. Unfavorable factors included recurrent depression, many drug changes, as well as low compliance with taking medication. Ms. Mai had a significantly higher treatment expectation for bPT than for treatment by her primary care doctor (CEQ: $\mathrm{SS}_{\mathrm{bPT}}=53, \mathrm{SS}_{\mathrm{GP}}=41$, range $=6-54)$. She stated that she preferred bPT because she did not want classic outpatient psychotherapy and preferred learning to handle her symptoms on her own, that it is easier to integrate online treatment, which is time and place independent, with her daily life, and that she found the idea of using new media exciting.

\section{Timeline}

Figure 3 represents the patient's important time sequences for diagnosis, intervention, and treatment outcomes (for further web-/app-based sequences, see online supplementary material).
Diagnostic Considerations and Clinical Findings

In her self-assessment, Ms. Mai reported impaired quality of life (EQ-5D-5L: index $=0.54$, range $=0-1)$, severe clinical insomnia (ISI: $S S=23$, range $=0-28$ ), and moderate to severe depressive symptoms (PHQ-9: SS $=17$, QIDS-SR: SS $=15$, range 0-27 each). In the external assessment, the study leaders used a structured clinical interview (Mini-International Neuropsychiatric Interview) to reach a diagnosis of recurrent depressive disorder, currently major depression. The therapist's differential diagnosis of recurrent depressive disorder with a current moderate episode (ICD-10 F33.1) was consistent with the finding of the consulting physician. The psychological findings revealed no suicidal thoughts or suicide attempts and no evidence of content-related thought disorder, psychotic events, dysfunction of self-awareness, or obsessive-compulsive disorder (no comorbid mental disorders). There were also no somatic findings reported by the primary care doctor.

\section{Therapeutic Intervention}

Type of Intervention. CBT-based blended short-term psychotherapy with IMIs (see above).

Course of Treatment. The bPT took place from January 7 , 2016 to May 3, 2016 (17 weeks duration of treatment). The Ap- 
pendix presents a detailed chronology of the course of treatment and the blending of face-to-face with web-/app-based interventions. Ms. Mai usually participated in the face-to-face sessions every 2 weeks, interspersed with six interactive online lessons (video/text, exercises) in the sequence agreed upon with the therapist (without the optional lesson). She logged in 17 times for the online lessons and spent a total of $5 \mathrm{~h}(320 \mathrm{~min})$ on these, with an average of $46 \mathrm{~min}$ per lesson. Her continuous app-based progress measurements (104 in total, 0.79 per day) showed improvement as well as stabilization of her mood and perceived self-esteem over the time of the treatment. Her statements about sleep and rumination were extremely variable. The therapist especially noted mood and sleep changes in the face-to-face sessions and sent three motivational reminders and five feedback messages about the exercises.

Changes in the Intervention and Notable Occurrences. Individual topics were dealt with and current stressors were addressed in the six face-to-face sessions. There was not enough time in all the face-to-face sessions to go into greater depth on the online lessons by using the interventions intended (e.g., situational analyses). Ms. Mai worked on two modules each of four online lessons in one pass instead of distributing them over 2 weeks. The exercises were sometimes done superficially and the therapist could only have a delayed corrective effect. Burdensome stressors occurred during the period of treatment (e.g., the death of a friend, returning to work, and an announcement of restructuring measures at work). The treatment duration was prolonged due to illness of the therapist and the patient and technical difficulties, so that there was no online lesson between the third and fourth face-to-face sessions.

Treatment by Primary Care Doctor during the Intervention Period. The primary care doctor's report covered six consultations with supportive discussions, SNRI medication (venlafaxine; planned dosage reduction), as well as recommendations on social activities and relaxation.

\section{Therapy Results}

Adherence. Ms. Mai attended all six therapy sessions, completed six online lessons (including exercises), and gave app ratings continuously (100\% adherence).

Face-to-Face Assessment. The patient rated the therapy sessions as very positive on the scales for therapeutic alliance (PSTB: $\mathrm{M}=$ 6 , range $=0-6)$, experiences of self-esteem $(M=6)$, and therapeutic progress $(M=5)$.

Working Alliance. The therapist assessed the therapeutic alliance as very positive (WAI-SRT: $S S=44$, range $=10-50$ ). This was in line with Ms. Mai's data (WAI-SF: SS = 57, range $=12-60$ ), who gave a maximum rating for the subscale Bond (WAI-SF: $\mathrm{SS}=20$, range $=4-20$ ) and also rated the technological working alliance very positively with the online treatment program (TAI-SF: SS = 79 , range $=12-84$ ).

Treatment Satisfaction. Ms. Mai in general expressed maximum satisfaction with the treatment (ZUF-8: SS $=32$, range = 8-32) and was highly satisfied with the online platform (SUS: $S S=75$, range $=0-100$ ). In the questionnaire (open answer format), she rated the technical introduction as a good start into the therapy. She gave maximum approval to the following statements ( 1 "totally disagree" to 5 "fully agree"): "The website and the app have supported the therapy" and "I would not hesitate to recommend an online mental health training program to a friend."

Undesired and Unexpected Effects. Ms. Mai had only positive things to say about the effects of the treatment (INEP: -3 to +3 ), e.g., an improved relationship with her spouse $(+3)$ and with her friends $(+2)$.

Efficacy Outcome Measure for Symptom Change by the End of Treatment. Ms. Mai reported mild depressive symptoms (PHQ-9:
SS = 7, QIDS-SR: SS = 8, range 0-27 each). The moderate-severe depressive symptoms had improved by ten points in the course of treatment, which is clinically significant (Reliable Change Index, RCI-PHQ- $9_{\mathrm{T} 0-\mathrm{T} 1}=2.42$ ), indicating that the patient was responding to the treatment. She reported a definitely improved quality of life (EQ-5D-5L: index $=0.86$ ) but a persistent severe sleep disorder (ISI: $\mathrm{SS}=23$ ).

Therapist/Physician-Assessed Results and Follow-Up Reports. In her treatment report to the primary care doctor, the therapist assessed the depressive symptoms as improved; she reflected, among other things, that the patient's reduced fear of losing control through engaging in relationship-focused therapy and her reduced skepticism about psychotherapy constituted treatment success. She reported the patient's willingness and desire to initiate continuing outpatient psychotherapy to stabilize the improvements and to work on other treatment topics in depth (e.g., sleep disorder). In the physician's report after completion of the intervention, the primary care doctor rated the depressive symptomatology as "much better".

Long-Term Results and Follow-Up. At follow-up measurements 3 and 9 months after the treatment ended, the PHQ-9 was 12 and 6 and the QIDS-SR was 9 and 6, respectively. This indicates a clinically significant response (PHQ-9: $\mathrm{RCI}_{\mathrm{T} 0-\mathrm{T} 2}=1.21, \mathrm{RCI}_{\mathrm{T} 0-\mathrm{T} 3}=$ 2.66) but with continuing subclinical-mild depressive symptoms. In the structured clinical interview at the 12-month follow-up, Ms. Mai no longer met the criteria for clinical depression (MDD: 3/9) and the symptoms were in remission. Although after 3 months (T2), she reported a diminished quality of life (EQ-5D-5L: index $\mathrm{x}_{\mathrm{T} 2}$ $=0.47$, index $\left.\mathrm{T}_{\mathrm{T} 3}=0.79\right)$ and moderate-severe insomnia (ISI: $\mathrm{SS}_{\mathrm{T} 2}=$ $22, \mathrm{SS}_{\mathrm{T} 3}=16$ ), both conditions had improved significantly after 9 months (T3). She stated at the last 12-month interview that for the past 6 months, she had stopped taking antidepressants and had had four probatory sessions and applied for psychotherapy to qualify for insurance coverage.

\section{Conclusion and Outlook}

The case report shows that bPT, a blended integration of Internet and mobile-based treatment elements into an outpatient CBT program, can lead to a substantial reduction of depressive symptoms with just six face-to-face therapy sessions. The patient was very satisfied with the combined treatment as well as the therapeutic and technological working relationship.

The case analysis illustrates numerous strengths of this type of treatment. The patient did not respond adequately to the medication according to the primary care doctor, and she followed his recommendation for bPT because she greatly valued the fact that the online treatment was independent of time and place and that she was able to reconcile the biweekly therapy sessions with her job and rural place of residence. She worked independently and flexibly at her own pace on the web-based CBT elements for treatment of depression and showed good adherence, unlike her problematic compliance with medication according to the primary care doctor. As with other studies, this case demonstrates that therapeutic guidance offered by IMIs leads to high adherence and a low risk of discon- 
tinuation [Johansson and Andersson, 2012; Baumeister et al., 2014; Erbe et al., 2017]. It also shows that treatment success is possible in people with a low level of education as well as those with severe depressive symptoms [Karyotaki et al., 2018]. The therapist's individual attention to the patient may have contributed to the high treatment satisfaction (e.g., stabilization when crises occurred). These advantages have also been mentioned by patients using a video-based bPT [Etzelmueller et al., 2018] and by blended therapists [Titzler et al., 2018]. The use of bPT reduced their inhibitions with regard to psychotherapy and functioned as a bridge to continuing psychotherapy. This reflects the potential to reach patient groups who "cannot take advantage of traditional services or do not want to" [Fischer, 2016].

The case report also highlights some weaknesses in the bPT that we used, for example, that more face-to-face sessions were needed to deepen the online lessons and adequately address individual treatment issues with behavioral therapeutic methods. The standardized online lessons were not able to address the comorbid sleep disorder, and the 13-week treatment period was too short, given some delays, to work on optional online lessons or to stabilize treatment successes.

The conclusions of this work are also subject to limitations. For one thing, it is not possible to generalize the statements; the individual case provides only hypothesisgenerating exploratory insights for a CBT-based bPT and was deliberately selected because of its successful results and the high adherence by the patient. On the other hand, each course of treatment depends on diverse case-related and contextual characteristics (e.g., comorbidities, chronification, self-management, motivation for treatment and change), and even in patients with similar demographic and disorder-specific characteristics, it could turn out to be different. Further limitations with potential influence on the intervention's effect arise from the study context of how the treatment is performed (e.g., high degree of standardization), characteristics of the therapist (e.g., experience, qualification, and sympathy), as well as possible confounding of factors because of the simultaneous treatment by the primary care doctor (e.g., side effects of taking/ stopping antidepressants, consultations of $6 \times 15 \mathrm{~min}$ ). However, in cases of severe depression, there is an indication for combination treatment with antidepressants [DGPPN et al., 2015]. Three more case reports were prepared for other sociodemographic and disorder-specific patients and treatment characteristics (e.g., men, elderly patients, comorbidity, nonresponders) for a more comprehensive analysis of strengths and weaknesses to optimize bPT [Titzler et al., 2019]. Case reports for younger patients and ethnic minorities, who were found, in a metaanalysis [Karyotaki et al., 2018], to show less response and remission in guided IMIs, would also be instructive.
Possible implications are that the implementation and further exploration of bPT should consider the following proposed changes: (a) variable treatment duration, (b) flexible adjustment of the frequency and sequence of faceto-face and online sessions, (c) an extended palette of optional online lessons for comorbid disorders and complaints that can be enabled as needed, and (d) integration of a tapering phase with a time-shifted face-to-face and online booster session to stabilize treatment success and prevent relapse. The limitations of the bPT used should also be explored and taken into account, such as the indicated high-frequency face-to-face sessions for suicidal or self-injuring patients, and the potentially limited indication for online treatment of those with low self-management skills, low technical/computer affinity, and factors inherent in the disease (e.g., psychotic experiences in severe depression, many comorbidities).

In practice, blended concepts are already in use through the combination of individual and group therapy. Also, the recommendations of the S3 Leitlinie (S3 Guideline) [DGPPN et al., 2015] already address the potential of evidence-based online treatments for unipolar depression as a low-threshold entry or link to regular psychotherapy. With regard to the Psychotherapy Guideline [Bundespsychotherapeutenkammer, 2018], the following are some possible areas of application of bPT: (a) for acute treatment of patients in mental crises, which is already offered by $66 \%$ of psychotherapists after a clinical consultation for rapid assistance, (b) for shortterm or long-term therapy, and (c) for optimization of care in rural areas, where the 5-month waiting period is very long and demand planning foresees fewer psychotherapists. Rural patients are more likely to be able to keep face-to-face appointments in the city if these are at longer intervals and to work on time- and place-independent online lessons between appointments. Psychotherapists could invest their freed-up resources in treating more patients by "delegating" parts of the treatment to IMIs and integrating these as a therapeutic extension. In the bPT we used, 50 min were invested every 2 weeks in face-to-face sessions and 25 min per week in therapeutic guidance of the online lessons, raising the intensity of the therapy; this would allow a savings of ca. 25$50 \%$ of therapist time, which is consistent with other studies [Erbe et al., 2017]. However, the validity of that statement is limited, as the therapists gave experiencebased estimates of the time needed for online monitoring in interviews and intervision; this should be recorded systematically in log files and in the performance documentation in the future. In the treatment process, the integration of digital technologies may result in improved transfer of learned coping strategies into everyday life, increase the treatment intensity, and/or facilitate the implementation of interventions (e.g., interac- 
tive and paperless homework, repeated situational analysis, app-based self-observation to assess cognitions, emotions, and behavior, access to online therapy tools and to evidence-based interventions for high-/ low-prevalence symptom profiles). Further research is needed, however, on the potential for increasing efficacy [Ebert et al., 2018], on the evidence and cost-effectiveness of large, high-quality, multicenter clinical trials [Baumeister et al., 2018], as well as on a combination with other schools of therapy. Results from several European countries can be expected soon [Kooistra et al., 2014; Kemmeren et al., 2016; Kleiboer et al., 2016].

The psychotherapeutic care landscape is changing in the digital age, and concepts such as bPT - the blending of offline and online treatment elements - can become a beneficial unit for all those involved.

\section{Acknowledgment}

The authors thank the patient and the therapist for their participation in the bPT.

\section{Statement of Ethics}

The patient, Ms. Mai (name changed), gave her written informed consent to the study and the preparation and publication of the case report.

\section{Disclosure Statement}

V. Egle and C. Gumbmann declare that they have no conflicts of interest. D.D. Ebert and M. Berking are shareholders and I. Titzler is on the research staff at GET.ON Institut GmbH, which offers IMIs in routine care through selective contracts with health insurance companies.

\section{Funding Sources}

The study was funded by the FP7 Health-2013-Innovation-1 Program of the European Commission (grant agreement number: 603098) within the framework of the E-COMPARED project (approved by DGP's Ethics Committee, registered on December 2, 2014 DRKS00006866)

\section{Author Contributions}

I. Titzler, D.D. Ebert, and M. Berking led the E-COMPARED project. I. Titzler developed the concept of the study/case report, supervised the bPT, collected, analyzed, and interpreted the data, and wrote the manuscript. V. Egle contributed to the conceptualization, data analysis, and interpretation of the case report as well as to the draft manuscript. C. Gumbmann contributed as an independent psychotherapist to the critical interpretation and presentation of the case report. D.D. Ebert gave critical feedback on the study and the bPT concept as well as the draft manuscript. All authors gave critical comments and authorized the final release of the manuscript. 


\section{Appendix}

\section{Description of Ms. Mai's Blended Psychotherapy}

\section{F2F Therapy Session 1: Initial interview and technical introduction (duration: 50 minutes)}

\begin{tabular}{l|ll} 
Type of intervention: & $\circ$ Technical introduction (installation of the app on the smartphone and account
\end{tabular}

- Relationship building

- Explanations of the technique

- Treatment overview

- Organizational activation, addressing technical misgivings)

- Overview of the structure of blended treatment

- Appointment for the next F2F session and the online lessons, as well as feedback messages

○ Mail with PDF manuals for the Moodbuster web and app

\section{Online Lesson 1: Introduction + Need To Know (duration: 97 minutes)}

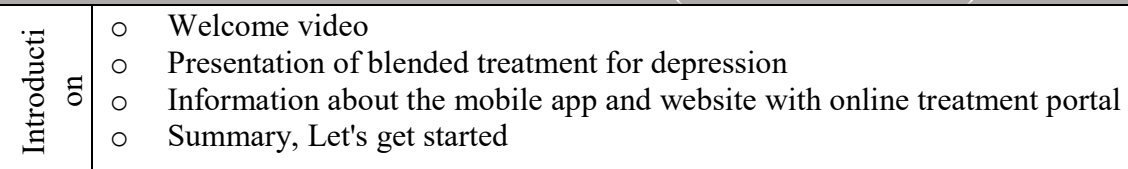

Psychoeducation about depression, life and treatment goals (by video, text):

○ Depressive symptoms, history, accompanying problems, causes, treatment options

- What are life and treatment goals? Tips for goal formulation

Exercise 1: Determining my life goals

B (1) Bring my private life to an acceptable level in interaction with my partner

\section{\begin{tabular}{l|l} 
(2) Do things more often with my best friends \\
\cline { 2 - 3 }
\end{tabular} $\Leftrightarrow \quad$ communicate them \\ ت्ठ (2) Learn to say "no" more often at my job to accepting more tasks than I can handle Z (3) Learn to relax more often}

B (1) Learn to not always think first about others, but to pay attention to my own concerns as well and be able to

Exercise 3: Rewards for achievement of goals - Help in creating a reward list

B Go to the movies, drink coffee or tea, listen to music, enjoy chocolate, etc.

Review and summary of the "Need To Know" lesson

ex Excerpt of feedback from the therapist to Ms. Mai: "... It's sometimes hard to keep on trying. Use the goals you have formulated to motivate yourself...."

\section{F2F Therapy Session 2 (duration: 55 minutes)}

\section{Type of intervention: $\quad$ ar Content/topics discussed:}

$\circ$ Relationship building - App mood ratings: "I don't like ups and downs. I still fall into a hole from time to

○ Exploration of life time...."

situation and stress $\quad$ - Inhibition toward psychotherapy: "I am ambivalent about psychologists and I'm not

factors sure how far I can open up"

- Psychoeducation

○ Review of the app

- Review of the online

lesson and planning the next one

- Self image: resolute, confrontational, a fighter, in need of harmony

- History of illness, vulnerability/stress factors: 7 years with a high workload (ca. 1012 hours per day); sleep disorders already three years before depression, persistent conflicts with partner, reintegration into work

as Homework: Online Lesson 2 "Getting Active"

\section{Online Lesson 2: Getting Active (duration: 156 minutes)}

\begin{tabular}{|c|c|}
\hline \multirow{4}{*}{ 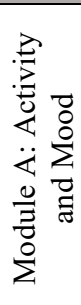 } & $\begin{array}{l}\text { Psychoeducation on activity and mood (by video + text): Relationship between behavior and positive impact of } \\
\text { mood, upward/downward spiral of depression, motivation }\end{array}$ \\
\hline & $\begin{array}{l}\text { Exercise 1: Help to create a list of enjoyable activities } \\
\text { \& Listen to music, spend a pleasant evening with friends, go for a walk, yoga }\end{array}$ \\
\hline & $\begin{array}{l}\text { Exercise 2: My activity level: How often I performed enjoyable activities } \\
\text { \& Very enjoyable activities: Table tennis (often), badminton (often), listening to music (often), pleasant evenings } \\
\text { with friends (often), yoga (sometimes), playing a game (sometimes) }\end{array}$ \\
\hline & Exercise 3: My calendar I: Entry of activities for the following week \\
\hline \multirow[b]{2}{*}{ 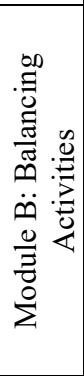 } & $\begin{array}{l}\text { Psychoeducation for activity planning: Identify obstacles to performing enjoyable activities, find a balance } \\
\text { between obligatory and enjoyable activities }\end{array}$ \\
\hline & $\begin{array}{l}\text { Planning activities } \\
\text { Exercise 4: Compile a list of necessary activities } \\
\text { O Clean, do my taxes, laundry, shopping } \\
\text { Exercise 5: Compile a list of possible obstacles to enjoyable activities } \\
\text { No desire, no time, too much other work } \\
\text { Exercise 6: Determining the number of necessary and enjoyable activities, taking into account the balance } \\
\text { between them and setting rewards for achievement of goals } \\
\text { क Reward: Buy a little something for myself }\end{array}$ \\
\hline
\end{tabular}




\begin{tabular}{|c|c|c|}
\hline & \multicolumn{2}{|c|}{$\begin{array}{l}\text { Exercise 7: My calendar II: Prepare an activity program for the coming week } \\
\text { Exercise 8: My activity program: Review the plan with regard to success of the goals set and difficulties } \\
\text { encountered, and observe mood changes } \\
\text { O Reasons the plan worked: I didn't do everything I had planned, but at least some of it } \\
\text { क Reasons the plan did not work: I had probably taken on too much at the beginning }\end{array}$} \\
\hline & \multicolumn{2}{|c|}{ Review and summary the lesson "Getting Active" } \\
\hline & \multicolumn{2}{|c|}{$\begin{array}{l}\text { Excerpt of feedback from the therapist to Ms. Mai: "... Always remember your rewards, too. If you } \\
\text { implemented your plan, you may also reward yourself for it." }\end{array}$} \\
\hline \multicolumn{3}{|c|}{ F2F Therapy Session 3 (duration: 56 minutes) } \\
\hline \multicolumn{2}{|c|}{$\begin{array}{ll}\text { Type of intervention: } \\
\circ & \text { Relationship building } \\
\circ & \text { Psychoeducation } \\
\circ & \text { Goal clarification } \\
\circ & \text { Behavioral activation } \\
\circ & \text { Review of the app } \\
\circ & \text { Review of the online } \\
& \text { lesson and planning the } \\
\text { next one }\end{array}$} & $\begin{array}{l}\text { Go Content/topics discussed: } \\
\text { - App ratings: Progression of sleep disturbances, exploration of situational stimuli and } \\
\text { exceptions, sleep hygiene rules } \\
\text { - Goal clarification: No life goals, help with a vision (e.g., "having a home that is really } \\
\text { a home"), concretization } \\
\text { - Work-related stress factors: Working through coping options, starting points for } \\
\text { positive change in the work-life balance, identifying warning signs of stress, } \\
\text { strengthening the perception of positive efforts by the boss, doing more enjoyable } \\
\text { activities in everyday life } \\
\text { os Homework: Online Lesson "Rethinking" }\end{array}$ \\
\hline \multirow[b]{2}{*}{ 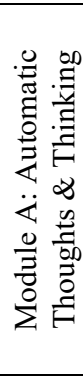 } & \multicolumn{2}{|c|}{$\begin{array}{l}\text { Psychoeducation (by video, text): Explanations and examples of automatic thoughts, thinking errors, beliefs, and } \\
\text { introduction of the ABC schema }\end{array}$} \\
\hline & \multicolumn{2}{|c|}{$\begin{array}{l}\text { Exercise 1: My ABC - Individual development through a problem situation (4-step plan) } \\
\text { क Describe the starting situation: At the job meeting, many planned upheavals and realignments over the } \\
\text { next four years are reported } \\
\text { क Evaluation: Identification of the automatic thought ("Will I keep my job?") and assessment of its } \\
\text { credibility (values: } 1-10)(9=\text { very credible) } \\
\text { क Consequences: Naming the reactions and the intensity of feelings (1-10): tense (8), agitated (8), anxious } \\
\text { (10) } \\
\text { क Identification of thinking errors: Catastrophizing, emotional reasoning }\end{array}$} \\
\hline \multirow{4}{*}{ 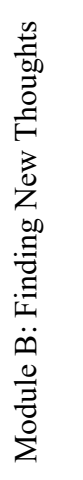 } & \multicolumn{2}{|c|}{$\begin{array}{l}\text { Psychoeducation: Strategies for rethinking (e.g., finding evidence, including previous experiences), three steps of } \\
\text { rethinking (questioning one's thoughts, helpful thoughts, revaluation) }\end{array}$} \\
\hline & \multicolumn{2}{|c|}{$\begin{array}{l}\text { Exercise 2: My rethinking - Exemplary use of the three steps of rethinking } \\
\text { क Questioning one's thoughts - finding evidence: "At every new restructuring in our company, } \\
\text { many colleagues have lost their jobs." } \\
\text { Finding evidence to the contrary: "I almost lost my job during one of the past restructurings, but I had } \\
\text { advocates who didn't want to give up the good work and insisted that I stay." } \\
\text { क Helpful thoughts: "After the restructuring I will find new tasks and will do my job well then too, and win } \\
\text { people over." } \\
\text { क Reassessing the credibility of the helpful thought (1-10): } 5\end{array}$} \\
\hline & \multicolumn{2}{|c|}{ Review and summary of Rethinking } \\
\hline & \multicolumn{2}{|c|}{$\begin{array}{l}\text { Excerpt of feedback from the therapist to Ms. Mai: "Replacing negative thoughts with new, more positive ones } \\
\text { is a task that requires constant practice. The first important step has already been taken." }\end{array}$} \\
\hline \multicolumn{3}{|c|}{ F2F Therapy Session 4 (duration: 52 minutes) } \\
\hline \multicolumn{2}{|c|}{$\begin{array}{ll}\text { Type of intervention: } \\
\circ & \text { Relationship building } \\
\circ & \text { Psychoeducation } \\
\circ & \text { Stabilization and } \\
& \text { emotion regulation } \\
\circ & \text { Review of the app } \\
\circ & \text { Planning the next online } \\
& \text { lesson }\end{array}$} & $\begin{array}{l}\text { pics discussed: } \\
\text { s: Intense feelings of mourning after the death of a friend, increased } \\
\text { at night, "brain is buzzing" } \\
\text { ith bereavement/emotion regulation: (a) guidance on differentiated } \\
\text { of physical signs of her emotions (dissatisfaction palpable in the stomach } \\
\text { ng of a foreign body in the stomach, visualized as } 50 \text { hot bricks, a sense of } \\
\text { ger in the stomach); (b) evaluation of the intensity (0-10): } 10 ;(\text { ) }) \\
\text { tion and validation: understanding the experience ("Are there reasons for } \\
k s ? ") ;(\text { d) model for a permissive attitude toward emotional expression: Let } \\
\text { y, accept comfort } \\
\text { Online Lesson "Solving Problems" }\end{array}$ \\
\hline \multicolumn{3}{|c|}{ F2F Therapy Session 5 (du } \\
\hline \multicolumn{2}{|c|}{$\begin{array}{l}\text { Type of intervention: } \\
\circ \quad \text { Relationship building } \\
\circ \quad \text { Psychoeducation } \\
\circ \\
\circ \quad \text { Behavioral activation } \\
\circ \text { Relapse Prevention }\end{array}$} & $\begin{array}{l}\text { Gontent/topics discussed: } \\
\text { - App ratings: "Good mood", increased use of self-cal } \\
\text { sleep problems, visualization of a peaceful image } \\
\text { Debriefing: Break from therapy (long illness, technic } \\
\text { good to give space to the "emotional side") }\end{array}$ \\
\hline
\end{tabular}




\begin{tabular}{|c|c|c|}
\hline & $\begin{array}{l}\text { Review of the app } \\
\text { Planning the next online } \\
\text { esson }\end{array}$ & $\begin{array}{l}\text { - Psychoeducation: Connection between suppression of emotions and emergence of } \\
\text { depression } \\
\text { - Dealing with dissatisfaction: Mindfully perceive things that are not beneficial, and } \\
\text { don't be silent, but address and change them; improved conflict management is } \\
\text { important for that } \\
\text { - Partnership conflicts: Possibilities for external support (e.g., couple counseling), } \\
\text { reinforcement for efforts at dialog with the partner } \\
\text { - Medication: Consideration of discontinuing antidepressants, psychoeducation } \\
\text { (motivation to consult with primary care doctor, procedure for tapering, possible side } \\
\text { effects) } \\
\text { or. Homework: Online Lesson } 4 \text { "Solving Problems" }\end{array}$ \\
\hline & S1 & blems (duration: 156 minutes) \\
\hline & Psychoeducation on $\mathrm{t}$ & pes of problems and effects of mood (by video, text) \\
\hline 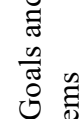 & $\begin{array}{l}\text { Exercise 1: My life go } \\
\text { 丹 II want to continu } \\
\text { treat problems as }\end{array}$ & $\begin{array}{l}\text { als - option to adapt or supplement the defined goals } \\
\text { to be aware of my strengths, to steer my actions and thoughts in positive directions and to } \\
\text { challenge." }\end{array}$ \\
\hline$\underset{1}{\ddot{1}}$ & $\begin{array}{l}\text { Exercise 2: My proble } \\
\text { 丹 Sleep deficit, worr }\end{array}$ & $\begin{array}{l}\text { ns - compilation of current concerns and problems } \\
\text { ies about the future, family conflicts, etc. }\end{array}$ \\
\hline & $\begin{array}{l}\text { Exercise 3: Classify m } \\
\text { solvable } \\
\text { 乃 Ms. Mai categoriz }\end{array}$ & $\begin{array}{l}\text { y problems - categorization as unimportant, important and unsolvable, or important and } \\
\text { ed all problems as "solvable" }\end{array}$ \\
\hline & Psychoeducation: $\mathrm{Cop}$ & ing options for different types of problems (Miracle Question, SMART Goals, etc.) \\
\hline 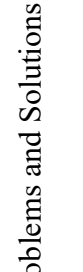 & $\begin{array}{l}\text { Exercise 4: Solving } \mathrm{m} \\
\text { problem, think about } \mathrm{s} \\
\text { Ð Describing the prol } \\
\text { 丹 Thinking about sol } \\
\text { see more positive effec } \\
\text { 丹 Choosing a solutio } \\
\text { 丹 Making a plan: } \mathrm{Co}\end{array}$ & $\begin{array}{l}\text { problems - working out a 6-step plan using your own situation as an example (describe the } \\
\text { lutions, choose, make a plan, take action, take stock) } \\
\text { lem: Worries about the future, changes at work } \\
\text { ttions: Although there are more tasks, I can make a difference, can contribute my ideas; I } \\
\text { s than negative, I get involved in committees } \\
\text { I I get involved more actively in appropriate committees } \\
\text { leagues support me, I participate actively, constructively contribute ideas }\end{array}$ \\
\hline $\begin{array}{l}\stackrel{0}{D} \\
\dot{\varphi} \\
\stackrel{0}{=}\end{array}$ & $\begin{array}{l}\text { Exercise 5: My trainin } \\
\beta \text { Goal: I want to br } \\
\beta \text { Activity: } \text { more cor }\end{array}$ & $\begin{array}{l}\text { g program - choice of a goal and an activity to achieve the goal } \\
\text { ng my private life with my partner to an acceptable level } \\
\text { imunication, we currently spend a lot of time talking }\end{array}$ \\
\hline Е & Review and summary & of "Solving Problems" \\
\hline$\sum^{e}$ & $\begin{array}{l}\text { Excerpt of feedba } \\
\text { them. It was certainly. }\end{array}$ & $\begin{array}{l}\text { k from the therapist: "It's great how you have taken on your problems and are working on } \\
\text { tressful, but it will be worthwhile." }\end{array}$ \\
\hline Onlin & ne Lesson 5: Sports and & Exercise (optional: not done) \\
\hline $\mathrm{F} 2 \mathrm{~F}$ & Therapy Session 6 (dur: & tion: 55 minutes) \\
\hline $\begin{array}{ll}\text { Type } \\
\circ & \mathrm{P} \\
\circ & \mathrm{R} \\
\circ & \mathrm{R} \\
\circ & \mathrm{P} \\
& 1 \\
\circ & \mathrm{C}\end{array}$ & $\begin{array}{l}\text { of intervention: } \\
\text { Psychoeducation } \\
\text { Reflection on therapy } \\
\text { Relapse Prevention } \\
\text { Planning the last online } \\
\text { esson } \\
\text { Completion of therapy }\end{array}$ & $\begin{array}{l}\text { Go Treatment issues/content: } \\
\text { - Review of treatment process and progress } \\
\text { 1. Workplace: Tasks are fun again, absolutely satisfied with the changes that have } \\
\quad \text { been initiated } \\
\text { 2. Spare time: Do more things again that restore her to herself } \\
\text { 3. Partnership: She approaches problems more diplomatically, responds less } \\
\text { irascibly, communicates more with her husband } \\
\text { 4. Sleep problems: Unchanged, referral to sleep outpatient sleep clinic } \\
\text { Psychoeducation for relapse prevention: Patient has a positive impression of } \\
\text { psychotherapy, information on how to search for psychotherapy, treatment options, } \\
\text { contact person in crises } \\
\text { Homework: "Preventing Relapse" }\end{array}$ \\
\hline
\end{tabular}

Online Lesson 6: Preventing Relapse (duration: 66 minutes)

Psychoeducation for relapse prevention (video/text material): Triggers for relapses, warning signs, response options, emergency plan, increasing mental well-being

Exercise 1: My goals - assessment of satisfaction with the achieved therapeutic goals

Goal 1: Learn to not always think first about others, but to pay attention to my own concerns as well and be able to communicate them (quite satisfied; note: no more concerns about the consequence if I say what I do not like)

$\checkmark$ Goal 2: Learn to say "no" more often at my job to accepting more tasks than I can handle during my working hours (very satisfied; note: I say where the limits are)

3 Goal 3: Learn to relax (rather satisfied; note: I imagine things that make me happy)

Exercise 2: My skills - review and reflection on the skills that Ms. Mai has learned

७ 1. Lesson "Need To Know": "I have recognized and ... also acknowledged my depression, ... I feel validated that I don't have to be ashamed, but deal with it openly." 
2. Lesson "Getting Active": "I do much more with friends and colleagues."

3. Lesson "Rethinking": "I've learned that it's possible to positively transform negative thoughts and feelings."

4. Lesson "Solving Problems": "I have changed my point of view. I can sometimes redefine my problems and turn them into challenges and plan actions...."

Exercise 3: My plan of action - identification of warning signs and helpful coping strategies

3 Warning signs: Worrying, sleep problems, negative thoughts, exhaustion, etc.

७ Response: Set a limit to time for rumination, undertake (sports) activities, ensure regular sleep and waking times, proceed in partial steps, formulate helpful thoughts, etc.

Review and summary of "Preventing Relapse"

Excerpt of feedback from the therapist to Ms. Mai: "You can be proud of yourself; during the last few weeks you have really hard and achieved a lot."

७ Thank you mail from Ms. Mai: "You taught me a lot of strength and motivation.... You as a therapist as well as the online program both helped me very much."

Legend: of face-to-face input from Ms. Mai; $\widehat{\vartheta}=$ web entries by Ms. Mai; $\mathscr{E}=$ feedback from the therapist

\section{References}

Baumeister H, Grässle C, Ebert DD, Krämer LV. Blended Psychotherapy - verzahnte Psychotherapie: Das Beste aus zwei Welten? PiD - Psychotherapie im Dialog. 2018; 19(4):33-8.

Baumeister H (Konsortialleitung), Pryss R, Reichert M, AOK Baden-Württemberg, Bosch BKK, MEDIVERBUND AG, Universität Erlangen Nürnberg: PSYCHOnlineTHERAPIE - Integration von Online-Interventionen in die ambulante Psychotherapie bei Patienten mit depressiven Störungen und Angststörungen. Innovationsfond: Neue Versorgungsformen. Laufzeit: 42 Monate. 2019. https://innovationsfonds.g-ba.de/projekte/neue-versorgungsformen/psychonlinetherapie-integration-von-online-interventionen-in-die-ambulante-psychotherapiebei-patienten-mit-depressiven-stoerungenund-angststoerungen.288.

Baumeister H, Reichler L, Munzinger M, Lin J. The impact of guidance on Internet-based mental health interventions - a systematic review. Internet Interv. 2014;1(4):205-15.

Berger T, Krieger T, Sude K, Meyer B, Maercker A. Evaluating an e-mental health program ("deprexis") as adjunctive treatment tool in psychotherapy for depression: results of a pragmatic randomized controlled trial. J Affect Disord. 2018 Feb;227:455-62.

Brooke J. SUS - A quick and dirty usability scale. In: Jordan PW, Thomas B, Weerdmeester BA, McClelland IL, editors. Usability Evaluation in Industry. London: Taylor \& Francis; 1996. p. 189-94.

Bundespsychotherapeutenkammer. Ein Jahr nach der Reform der Psychotherapie-Richtlinie. Wartezeiten 2018. BPtK-Studie. 2018. https://www.bptk.de/wp-content/uploads/2019/01/20180411_bptk_studie_wartezeiten_2018.pdf.

Carlbring P, Andersson G, Cuijpers P, Riper H, Hedman-Lagerlöf E. Internet-based vs. faceto-face cognitive behavior therapy for psychiatric and somatic disorders: an updated systematic review and meta-analysis. Cogn Behav Ther. 2018 Jan;47(1):1-18.

Cohen $\mathrm{H}$. How to write a patient case report. Am J Health Syst Pharm. 2006 Oct;63(19):188892.
Cuijpers P, de Wit L, Kleiboer A, Karyotaki E, Ebert DD. Problem-solving therapy for adult depression: an updated meta-analysis. Eur Psychiatry. 2018 Feb;48:27-37.

Devilly GJ, Borkovec TD. Psychometric properties of the credibility/expectancy questionnaire. J Behav Ther Exp Psychiatry. 2000 Jun; 31(2):73-86.

DGPPN, BÄK, KBV, AWMF, AkdÄ, BPtK, et al., editors. S3-Leitlinie/Nationale Versorgungsleitlinie Unipolare Depression - Langfassung, ed 2. 2015.

Ebert DD, Van Daele T, Nordgreen T, Karekla M, Compare A, Zarbo C, et al. Internet- and Mobile-Based Psychological Interventions: Applications, Efficacy, and Potential for Improving Mental Health. Eur Psychol. 2018;23(2): $167-87$.

Ellis A. The revised ABC's of Rational-Emotive Therapy (RET). J Ration Cogn Ther. 1991; 9(3):139-72.

Erbe D, Eichert HC, Rietz C, Ebert D. Interformat reliability of the patient health questionnaire: validation of the computerized version of the PHQ-9. Internet Interv. 2016 Jun;5:1-4.

Erbe D, Eichert HC, Riper H, Ebert DD. Blending Face-to-Face and Internet-Based Interventions for the Treatment of Mental Disorders in Adults: systematic Review. J Med Internet Res. 2017 Sep;19(9):e306.

Etzelmueller A, Radkovsky A, Hannig W, Berking $M$, Ebert DD. Patient's experience with blended video- and internet-based cognitive behavioural therapy service in routine care. Internet Interv. 2018 Feb;12:165-75.

Fischer F. eHealth in Deutschland. Berlin/Heidelberg: Springer; 2016

Flückiger C, Regli D, Zwahlen D, Hostettler S, Caspar F. Der Berner Patienten- und Therapeutenstundenbogen 2000. Z Klin Psychol Psychother. 2010;39(2):71-9.

Gagnier JJ, Kienle G, Altman DG, Moher D, Sox H, Riley D; CARE Group. The CARE Guidelines: Consensus-based Clinical Case Reporting Guideline Development. Glob Adv Health Med. 2013 Sep;2(5):38-43.

Gerste B, Roick C. Prävalenz und Inzidenz sowie Versorgung depressiver Erkrankungen in Deutschland - eine Analyse auf Basis der in Routinedaten dokumentierten Depressions- diagnosen. In: Versorgungs-Report 2013/14. Schwerpunkt: Depression. Stuttgart: Schattauer; 2014. p. 21-54.

Hautzinger M. Kognitive Verhaltenstherapie bei Depressionen. 7th ed. Weinheim, Basel: Beltz Verlag; 2013.

Hawley LL, Padesky CA, Hollon SD, Mancuso E, Laposa JM, Brozina K, et al. Cognitive-Behavioral Therapy for Depression Using Mind Over Mood: CBT Skill Use and Differential Symptom Alleviation. Behav Ther. 2017 Jan;48(1):29-44. Herdman M, Gudex C, Lloyd A, Janssen M, Kind P, Parkin D, et al. Development and preliminary testing of the new five-level version of EQ-5D (EQ-5D-5L). Qual Life Res. 2011 Dec; 20(10):1727-36.

Jacobi F, Höfler M, Siegert J, Mack S, Gerschler A, Scholl L, et al. Twelve-month prevalence, comorbidity and correlates of mental disorders in Germany: the Mental Health Module of the German Health Interview and Examination Survey for Adults (DEGS1-MH). Int J Methods Psychiatr Res. 2014 Sep;23(3):304-19.

Johansson R, Andersson G. Internet-based psychological treatments for depression. Expert Rev Neurother. 2012 Jul;12(7):861-9.

Karyotaki E, Ebert DD, Donkin L, Riper H, Twisk J, Burger S, et al. Do guided internet-based interventions result in clinically relevant changes for patients with depression? An individual participant data meta-analysis. Clin Psychol Rev. 2018 Jul;63:80-92.

Kemmeren LL, van Schaik DJ, Riper H, Kleiboer AM, Bosmans JE, Smit JH. Effectiveness of blended depression treatment for adults in specialised mental healthcare: study protocol for a randomised controlled trial. BMC Psychiatry. 2016 Apr;16(1):113.

Kemmeren LL, van Schaik A, Smit JH, Ruwaard J, Rocha A, Henriques M, et al. Unraveling the black box: exploring usage patterns of a blended treatment for depression in a multicenter study. JMIR Ment Health. 2019 Jul;6(7):e12707.

Kleiboer A, Smit J, Bosmans J, Ruwaard J, Andersson G, Topooco N, et al. European COMPARative Effectiveness research on blended Depression treatment versus treatment-as-usual (ECOMPARED):study protocolfora randomized controlled, non-inferiority trial in eight European countries. Trials. 2016 Aug; 17(1):387. 
Königbauer J, Letsch J, Doebler P, Ebert DD, Baumeister $\mathrm{H}$. Internet- and mobile-based depression interventions for people with diagnosed depression: a systematic review and meta-analysis. J Affect Disord. 2017 Dec;223: $28-40$.

Kooistra LC, Ruwaard J, Wiersma JE, van Oppen P, van der Vaart R, van Gemert-Pijnen JE, et al. Development and initial evaluation of blended cognitive behavioural treatment for major depression in routine specialized mental health care. Internet Interv. 2016 Jan;4: 61-71.

Kooistra LC, Wiersma JE, Ruwaard J, van Oppen P, Smit F, Lokkerbol J, et al. Blended vs. faceto-face cognitive behavioural treatment for major depression in specialized mental health care: study protocol of a randomized controlled cost-effectiveness trial. BMC Psychiatry. 2014 Oct; 14(1):290.

Ladwig I, Rief W, Nestoriuc Y. Welche Risiken und Nebenwirkungen hat Psychotherapie? Entwicklung des Inventars zur Erfassung Negativer Effekte von Psychotherapie (INEP). Verhaltenstherapie. 2014;24(4):252-63.

Ledochowski L, Stark R, Ruedl G, Kopp M. Körperliche Aktivität als therapeutische Intervention bei Depression. Nervenarzt. $2017 \mathrm{Jul}$; 88(7):765-78.

Lindhiem O, Bennett CB, Rosen D, Silk J. Mobile technology boosts the effectiveness of psychotherapy and behavioral interventions: a metaanalysis. Behav Modif. 2015 Nov;39(6):785804.

Ly KH, Topooco N, Cederlund H, Wallin A, Bergström J, Molander O, et al. Smartphone-Supported versus Full Behavioural Activation for Depression: A Randomised Controlled Trial. PLoS One. 2015 May;10(5):e0126559.

Mack S, Jacobi F, Gerschler A, Strehle J, Höfler M, Busch MA, et al. Self-reported utilization of mental health services in the adult German population - evidence for unmet needs? Results of the DEGS1-Mental Health Module (DEGS1-MH). Int J Methods Psychiatr Res. 2014 Sep;23(3):289-303.
Martell CR, Dimidjian S, Herman-Dunn R. Behavioral activation for depression: A clinician's guide. New York: Guilford Press; 2010.

Munder T, Wilmers F, Leonhart R, Linster HW, Barth J. Working Alliance Inventory-Short Revised (WAI-SR): psychometric properties in outpatients and inpatients. Clin Psychol Psychother. 2010 May-Jun;17(3):231-9.

Rush AJ, Trivedi MH, Ibrahim HM, Carmody TJ, Arnow B, Klein DN, et al. The 16-Item Quick Inventory of Depressive Symptomatology (QIDS), clinician rating (QIDS-C), and selfreport (QIDS-SR): a psychometric evaluation in patients with chronic major depression. Biol Psychiatry. 2003 Sep;54(5):573-83.

Schmidt J, Lamprecht F, Wittmann WW. Satisfaction with inpatient management. Development of a questionnaire and initial validity studies. Psychother Psychosom Med Psychol. 1989 Jul;39(7):248-55. German.

Sethi S, Campbell AJ, Ellis LA. The use of computerized self-help packages to treat adolescent depression and anxiety. J Technol Hum Serv. 2010;28(3):144-60.

Sheehan DV, Lecrubier Y, Sheehan KH, Amorim P, Janavs J, Weiller E, et al. The Mini-International Neuropsychiatric Interview (M.I.N.I.): the development and validation of a structured diagnostic psychiatric interview for DSM-IV and ICD-10. J Clin Psychiatry. 1998; 59 Suppl 20:22-33.

Sturmey P. Behavioral activation is an evidencebased treatment for depression. Behav Modif. 2009 Nov;33(6):818-29.

Thorndike FP, Ritterband LM, Saylor DK, Magee JC, Gonder-Frederick LA, Morin CM. Validation of the Insomnia Severity Index as a web-based measure. Behav Sleep Med. 2011; 9(4):216-23.
Titzler I, Egle V, Ebert DD. Blending internetand mobile-based treatment for depression with on-site psychotherapy: case report of a 63-year old patient. Oral poster presentation at the 10th Scientific Meeting of the International Society for Research on Internet Interventions (ISRII). Auckland, 2019.

Titzler I, Saruhanjan K, Berking M, Riper H, Ebert DD. Barriers and facilitators for the implementation of blended psychotherapy for depression: a qualitative pilot study of therapists' perspective. Internet Interv. 2018 Jan; 12:150-64.

Vallury KD, Jones M, Oosterbroek C. Computerized Cognitive Behavior Therapy for Anxiety and Depression in Rural Areas: A Systematic Review. J Med Internet Res. 2015 Jun; 17(6):e139.

van der Vaart R, Witting M, Riper H, Kooistra L, Bohlmeijer ET, van Gemert-Pijnen LJ. Blending online therapy into regular face-to-face therapy for depression: content, ratio and preconditions according to patients and therapists using a Delphi study. BMC Psychiatry. 2014 Dec;14(1):355.

Virués-Ortega J, Rodríguez R. Guidelines for clinical case reports in behavioral clinical psychology. Int J Clin Health Psychol. 2008;8: 765-77.

Vis C, Kleiboer A, Prior R, Bønes E, Cavallo M, Clark SA, et al. Implementing and up-scaling evidence-based eMental health in Europe: the study protocol for the MasterMind project. Internet Interv. 2015;2(4):399-409.

World Health Organization. The Global Burden of Disease - 2004 update. 2008. https://www. who.int/healthinfo/global_burden_disease/ GBD_report_2004update_full.pdf.

Zwerenz R, Becker J, Knickenberg RJ, Siepmann M, Hagen K, Beutel ME. Online Self-Help as an Add-On to Inpatient Psychotherapy: Efficacy of a New Blended Treatment Approach. Psychother Psychosom. 2017;86(6):341-50. 